EPJ Web of Conferences 114.02126 (2016)

DOI: $10.1051 /$ epjconf/201611402126

(C) Owned by the authors, published by EDP Sciences, 2016

\title{
Scour depth estimation using an equation based on wind tunnel experiments
}

\author{
Takayuki Tsutsui ${ }^{1, a}$ \\ ${ }^{1}$ Department of Mechanical Engineering, The National Defense Academy, 1-10-20 Hashirimizu, Yokosuka, Kanagawa 239-8686, Japan
}

\begin{abstract}
Scour is the result of degradation and aggradation by wind or moving fluid in the front and back of a pole standing in sand, respectively, and is often observed at the bottom of bridge piers in rivers. In this study, we propose a method of estimating the scour depth around a cylindrical structure standing in sand. The relationships among the depth of the scour, the aspect ratio of the structure (= height/diameter), the fluid velocity, and the sand properties (particle size and density) were determined experimentally using a wind tunnel. The experiments were carried out under clear-water scour conditions. In the experiments, the aspect ratio of the cylindrical structure, the fluid velocity, and the sand particle size were varied systematically. The diameters of the structure were 20,40 , and $60 \mathrm{~mm}$, and the aspect ratio was varied from 0.25 to 3.0. Sand particles of four sizes $(200,275,475$, and $600 \mu \mathrm{m})$ were used in the experiment, and the velocity was varied from 4 to $11 \mathrm{~m} / \mathrm{s}$. The depth and radius of the scour were measured. As a result, we have developed an equation for estimating the scour depth that uses the aspect ratio, fluid velocity, and sand particle size as parameters.
\end{abstract}

\section{Introduction}

Scour is the result of the erosive action of flowing water, which excavates and carries away material from riverbeds and around the piers of bridges. Scour can be found not only in rivers but also in sand [1] and snow [2]; the basic mechanism of scour is the same in these three cases.

The scour mechanism is caused by three vortex systems: horseshoe, wake, and trailing [3, 4]. In particular, studies have investigated wake vortices, which are also called roll-up vortices. A roll-up vortex is a spiral vortex that can be observed behind a pole [5]. In this vortex mechanism, sand is flung up by the roll-up vortex and falls down behind the pole. Graf and Istiarto [6] and Pasiok and Stilger-Szydlo [7] call this type of vortex the wake vertical vortex.

Numerous studies have also estimated the scour depth around bridge piers in rivers (e.g., [8]). Such estimates are valuable in the field of civil engineering. Therefore, we propose a method for estimating the scour depth in an air-sand system. Water-sand and air-sand systems are defined as environments in which scour is caused by water and air, respectively.

In this study, to determine the important factors that influence scour in the air-sand system, we experimentally investigated the scour depth around a cylindrical structure in the sand of a riverbed by using a wind tunnel. We systematically varied the diameter and aspect ratio of the cylindrical structure, the particle size of the bed material, and the fluid velocity and optically measured the scour depth and radius. The main factors that influenced the scour were determined by analyzing the data, and we define a simplified equation for estimating the scour depth.

\section{Experimental apparatus and methods}

The experimental coordinate system and a schematic of the low-speed wind tunnel used in this study are shown in figures 1 and 2 , respectively. The experiments were conducted in a low-speed wind tunnel with dimensions of $1000 \mathrm{~mm} \times 400 \mathrm{~mm} \times 300 \mathrm{~mm}$. The diameter and height of the cylindrical structure are denoted by $\mathrm{D}$ and $\mathrm{H}$, respectively. The scour depth is denoted by $\mathrm{Z}$ and is measured from the ground level to the deepest point in the scour. The radius $\mathrm{R}$ is the distance from the front surface of the cylindrical structure to the front edge of the scour. Cylindrical structures made of acrylic resin with diameters of 20,40 , and $60 \mathrm{~mm}$ were used in this study. The aspect ratio $\mathrm{H} / \mathrm{D}$ of the cylindrical structures was varied from 0.25 to 3.0 , and the fluid velocity $\mathrm{U}$ from 4 to $11 \mathrm{~m} / \mathrm{s}$. The bed materials were sands of varying particle size. The properties of the different bed materials (particle size $d s$, density $\rho_{s}$, and angle of repose $\theta$ ) are given in table 1.

Experiments were designed and conducted for different velocities, diameters, aspect ratios, and sand particle sizes. The scour radius and depth were measured by a video camera and a laser rangefinder, as shown in figure 3 .

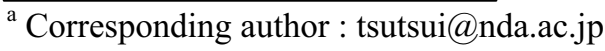




\section{Results and discussion}

\subsection{Differences between air-sand and water- sand systems}

Figure 4 shows an example of the scour depth and radius as functions of time t. Both have the same profile; that is, they first change rapidly and subsequently increase monotonically, ultimately reaching their maximum (equilibrium) values. To compare the air-sand and watersand systems, the experimental data under the conditions of the water-sand system in a flume are plotted against time $t$ in figure 5 . The profile is the same as that in figure 4. These data are transformed into dimensionless values and plotted on a single graph (figure 6). Figure 6 shows the logarithmically nondimensional scour depth Z / D and radius $\mathrm{R} / \mathrm{D}$ as functions of the nondimensional time $\mathrm{U} t$ / D. The progress in the depth and radius changes at approximately $\mathrm{U} \mathrm{t} / \mathrm{D}=3 \times 10^{4}$, which is the deflection point. This point defines the earlier $\left(\mathrm{U} t / \mathrm{D} \leq 3 \times 10^{4}\right)$ and later $\left(\mathrm{Ut} / \mathrm{D} \geq 3 \times 10^{4}\right)$ periods.

The scour depth and radius are related to the angle of repose of the bed material. Figure 7 shows the slope of the scour $\left[=\tan ^{-1}(\mathrm{Z} / \mathrm{R})\right]$. The slope is $35^{\circ}$, which is the angle of repose of $200 \mu \mathrm{m}$ sand. We can estimate the radius from the depth; therefore, we consider only the depth for the remainder of this paper.

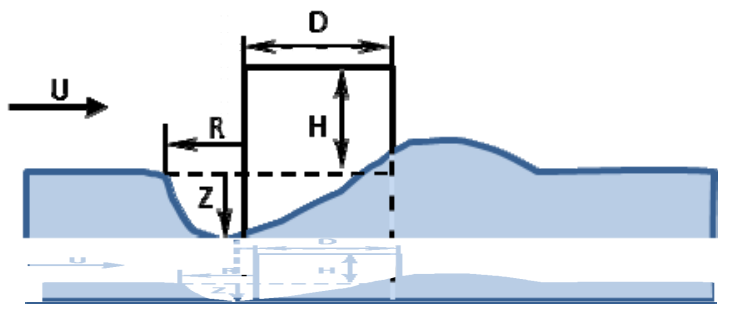

Figure 1. Flow geometry and coordinate system

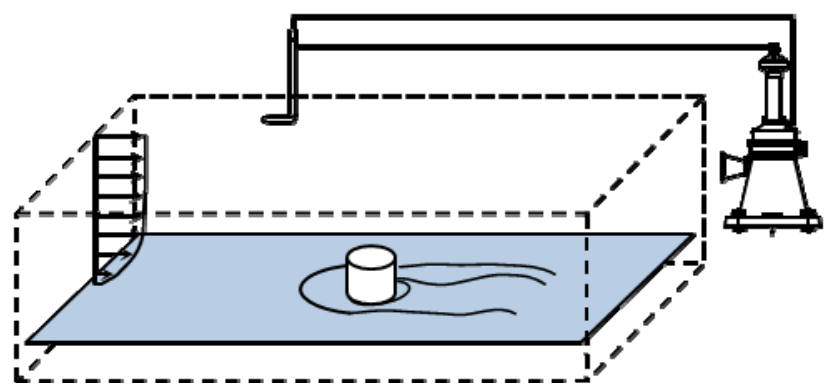

Figure 2. Schematic of law speed wind tunnel

Table 1. Property of bed material

\begin{tabular}{|c|c|c|c|}
\hline $\begin{array}{c}\text { mean size } \\
\mathrm{d}_{\mathrm{s}}[\mu \mathrm{m}]\end{array}$ & $\begin{array}{c}\text { size range } \\
\mathrm{d}_{\mathrm{s}}[\mu \mathrm{m}]\end{array}$ & $\begin{array}{c}\text { density } \\
\rho_{\mathrm{s}}\left[\mathrm{kg} / \mathrm{m}^{3}\right]\end{array}$ & $\begin{array}{c}\text { angle of repose } \\
\theta_{\mathrm{s}}[\mathrm{deg} .]\end{array}$ \\
\hline 200 & $180-212$ & 2600 & 35 \\
\hline 275 & $250-300$ & 2600 & 32 \\
\hline 475 & $450-500$ & 2300 & 35 \\
\hline 600 & $575-625$ & 2300 & 34 \\
\hline
\end{tabular}

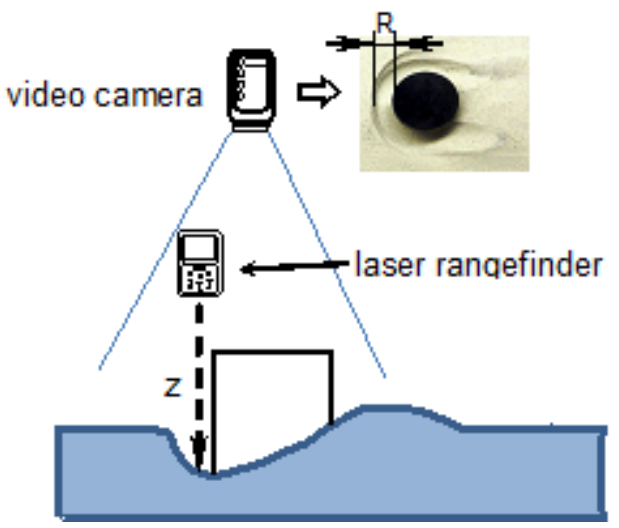

Figure 3. Measurement system

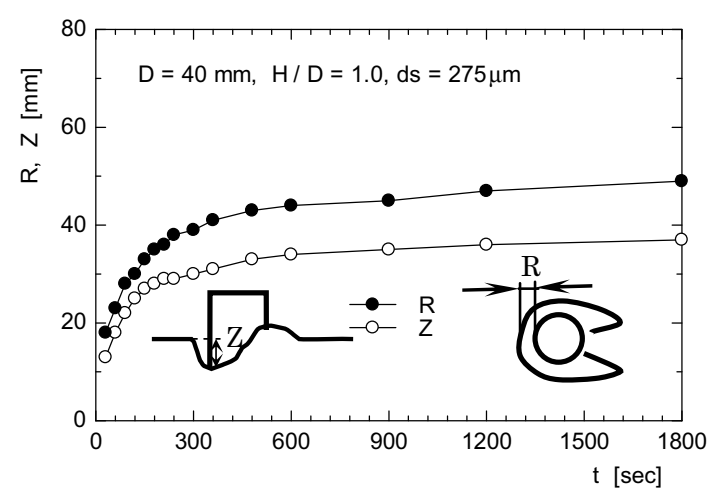

Figure 4. Example of scour depth and radius in air - sand field by wind tunnel $(\mathrm{D}=40 \mathrm{~mm}, \mathrm{U}=7 \mathrm{~m} / \mathrm{s}, \mathrm{ds}=275 \mathrm{~mm})$

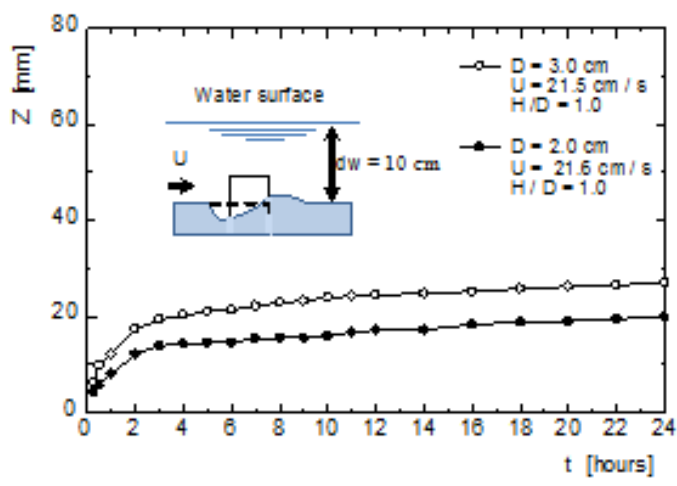

Figure 5. Example of scour depth in water - sand field by flume (modified after T. Euler and J. Herget, 2012, p. 41)

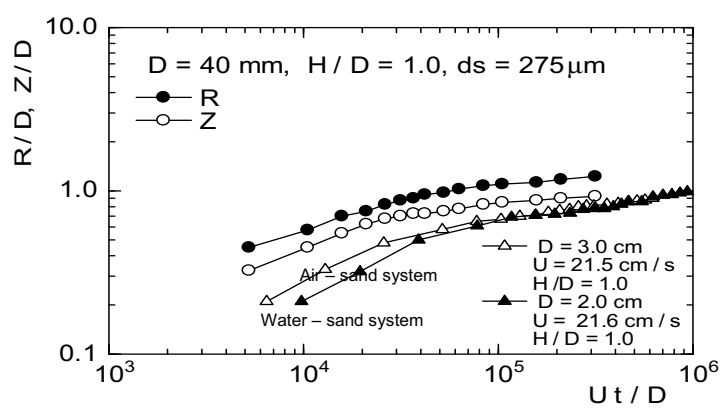

Figure 6. Comparison with non-dimensional scour depth and radius in two different fields 

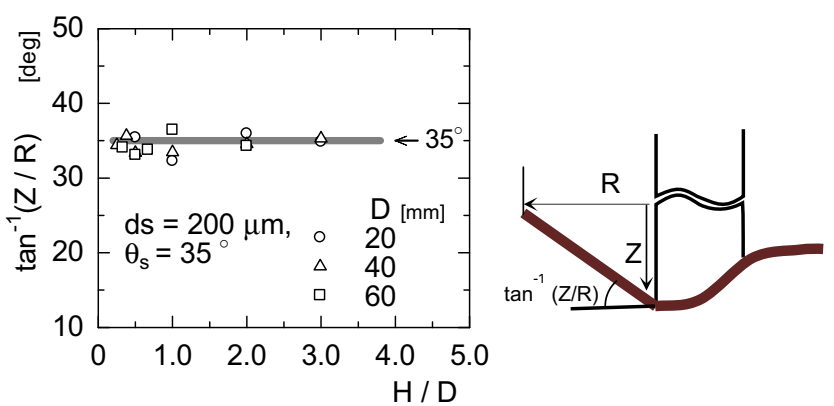

Figure 7. Slope of the scour $(\mathrm{ds}=200 \mathrm{~mm})$

(a) $\mathrm{H} / \mathrm{D}=0.5$

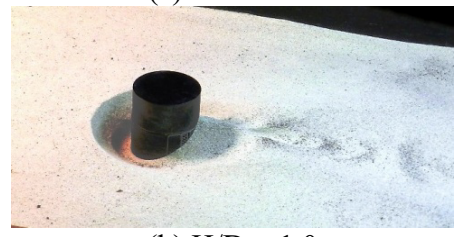

(b) $\mathrm{H} / \mathrm{D}=1.0$

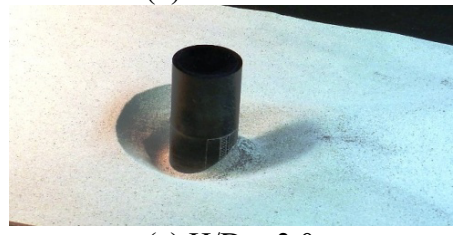

(c) $\mathrm{H} / \mathrm{D}=3.0$

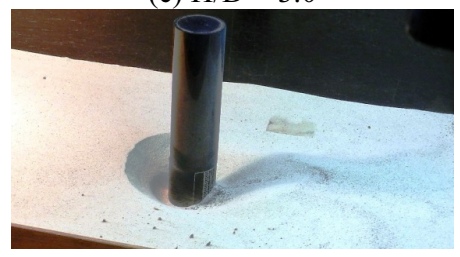

Figure 8. Photograph of scour hole changed by aspect ratio $(\mathrm{D}=40 \mathrm{~mm}, \mathrm{U}=6 \mathrm{~m} / \mathrm{s}, 300$ second elapsed)

(a) $\mathrm{ds}=200 \mathrm{~mm}$

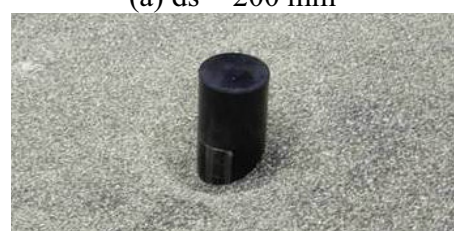

(b) $\mathrm{ds}=275 \mathrm{~mm}$

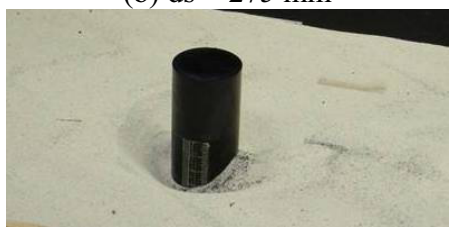

(c) $\mathrm{ds}=475 \mathrm{~mm}$

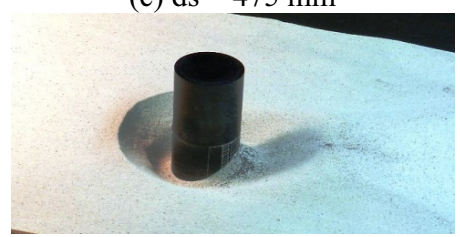

Figure 9. Photograph of scour hole changed by particle size (D $=40 \mathrm{~mm}, \mathrm{U}=6 \mathrm{~m} / \mathrm{s}, \mathrm{H} / \mathrm{D}=1.0,300$ second elapsed)

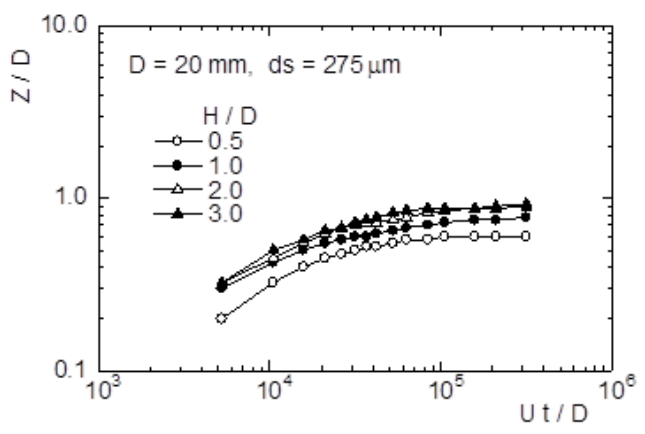

Figure 10. Scour depth changed by aspect ratio $(D=20 \mathrm{~mm}$, ds $=275 \mathrm{~mm}$ )

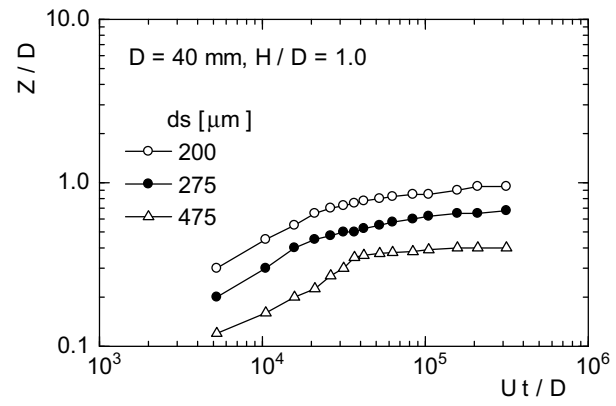

Figure 11. Scour depth changed by particle size $(D=40 \mathrm{~mm}, \mathrm{H}$ / $\mathrm{D}=1.0)$

\subsection{Progress of scour}

Figure 8 shows photographs of scour holes for different aspect ratios $(\mathrm{H} / \mathrm{D}=0.5,1.0$, and 3.0$)$ obtained 300 seconds after turning on the wind tunnel fan. The degradation around the cylinder increases with increasing aspect ratio. Figure 9 shows photographs of scour holes for the different particle sizes investigated in this study. The scour depth increases with decreasing particle diameter. The photographs show the influence of the particle size on the scour hole characteristics.

According to figures 10 and 11, the aspect ratio and particle size have a large influence on the scour depth

\subsection{Scour depth estimation by dimensionless analysis}

Dimensionless quantities are introduced for the purpose of discussing the proposed scour depth estimation method. The physical quantities that determine the equilibrium scour depth $\mathrm{Z}_{\mathrm{s}}$ are the diameter $\mathrm{D}$ and height $\mathrm{H}$ of the cylindrical structure, the fluid velocity $U$, the sediment particle size $d$, the acceleration due to gravity g, the viscosity of air $\mu$, the density of air $\rho$, and the density of the sediment $\rho$ s. The dimensions of these quantities are defined in terms of mass $\mathrm{M}$, length $\mathrm{L}$, and time $\mathrm{T}$, and the dimensional equations given in terms of $\mathrm{M}, \mathrm{L}$, and $\mathrm{T}$ are called MLT equations. The dimensions of the given quantities are $\mathrm{Zs}_{\mathrm{s}}=[\mathrm{L}], \mathrm{D}=[\mathrm{L}], \mathrm{H}=[\mathrm{L}], \mathrm{U}=\left[\mathrm{L} \mathrm{T}^{-1}\right], \mathrm{ds}_{\mathrm{s}}=$ $[\mathrm{L}], \mathrm{g}=\left[\mathrm{L} \mathrm{T}^{-2}\right], \mu=\left[\mathrm{M} \mathrm{T}^{-1} \mathrm{~L}^{-1}\right], \rho=\rho_{\mathrm{s}}=\left[\mathrm{M} \mathrm{L}^{-3}\right]$.

The dimensionless equilibrium scour depth $\mathrm{Z}_{\mathrm{s}} / \mathrm{D}$ is 


$$
Z_{s} / D=K D^{a} H^{b} U^{c} d s^{d} g^{e} \mu^{f} \rho^{g} \rho_{s}^{h}
$$

where $K$ is a constant and a, b, c, d, e, f, g, and h are exponents. Writing this as an MLT equation, we have

$0=$

$$
[\mathrm{L}]^{\mathrm{a}}[\mathrm{L}]^{\mathrm{b}}\left[\mathrm{L} \mathrm{T}^{-1}\right]^{\mathrm{c}}[\mathrm{L}]^{\mathrm{d}}\left[\mathrm{L} \mathrm{T}^{-2}\right]^{\mathrm{e}}\left[\mathrm{M} \mathrm{T}^{-1} \mathrm{~L}^{-1}\right]^{\mathrm{f}}\left[\mathrm{M} \mathrm{L}^{-3}\right]^{\mathrm{g}}\left[\mathrm{M} \mathrm{L}^{-3}\right]^{\mathrm{h}} \text {. }
$$

Next, we equate the powers of each dimension on the right and left-hand sides of equation (2), where $M$ and $\mathrm{L}^{-1}$ are always shown together as $\mathrm{ML}^{-1}$. We equate powers of $\mathrm{ML}^{-1}$, length $\mathrm{L}$, and time $\mathrm{T}$.

$$
\begin{gathered}
\mathrm{M} \mathrm{L}^{-1}: \mathrm{f}+\mathrm{g}+\mathrm{h}=0, \\
\mathrm{~L}: \mathrm{a}+\mathrm{b}+\mathrm{c}+\mathrm{d}+\mathrm{e}-2 \mathrm{~g}-2 \mathrm{~h}=0, \\
\mathrm{~T}:-\mathrm{c}-2 \mathrm{e}-\mathrm{f}=0
\end{gathered}
$$

The numbers of the reference and basic dimensions are 8 and 3 . We thus obtain the following five dimensionless quantities:

$$
\begin{gathered}
\mathrm{a}=-\mathrm{b}-\mathrm{d}+\mathrm{e}-\mathrm{f}, \\
\mathrm{c}=-2 \mathrm{e}-\mathrm{f}, \\
\mathrm{g}=-\mathrm{f}-\mathrm{h}, \\
\frac{\mathrm{Z}_{\mathrm{s}}}{\mathrm{D}}=\mathrm{K}\left(\frac{\mathrm{H}}{\mathrm{D}}\right)^{\mathrm{b}}\left(\frac{\mathrm{d}_{\mathrm{s}}}{\mathrm{D}}\right)^{\mathrm{d}}\left(\frac{\mathrm{Dg}}{\mathrm{U}^{2}}\right)^{\mathrm{e}}\left(\frac{\mu}{\mathrm{UD} \rho}\right)^{\mathrm{f}}\left(\frac{\rho_{\mathrm{s}}}{\rho}\right)^{\mathrm{h}} .
\end{gathered}
$$

We can combine these dimensionless quantities to simplify them:

$$
\begin{aligned}
\left(\frac{d_{s}}{D}\right) /\left(\frac{\mu}{U \rho \rho}\right) & =\left(\frac{U d_{s}}{\mu / \rho}\right)=\operatorname{Res}_{s} \\
1 / \sqrt{\left(\frac{d_{s}}{D}\right)\left(\frac{D g}{U^{2}}\right)\left(\frac{\rho_{s}}{\rho}\right)}= & \frac{U}{\sqrt{\frac{\rho_{s}}{\rho} d_{s} g}} \Rightarrow \frac{U}{\sqrt{\frac{\left(\rho_{s}-\rho\right)}{\rho} d_{s} g}}=\frac{U}{\sqrt{\left(\rho_{s} / \rho-1\right) d_{s} g}} \\
& =N_{s}
\end{aligned}
$$

where $\mathrm{H} / \mathrm{D}, \mathrm{Re}_{\mathrm{s}}$, and $\mathrm{N}_{\mathrm{s}}$ are the aspect ratio, sediment Reynolds number, and sediment number, respectively. Furthermore, $\rho_{\mathrm{s}} / \rho$ is the sediment specific gravity, which we modified as $(\rho s-\rho) / \rho$ to allow the introduction of $N_{s}$. As a result, $Z_{s} / D$ can be represented as a function of three dimensionless quantities:

$$
Z_{s} / D=f\left(H / D, R e s, N_{s}\right) .
$$

Figure 12 shows the correlation between the equilibrium scour depth $\mathrm{Z}_{\mathrm{s}} / \mathrm{D}$ and the aspect ratio H / D. The $\log$ of $\mathrm{Z}_{\mathrm{s}} / \mathrm{D}$ is proportional to the $\log$ of $\mathrm{H} / \mathrm{D}$. We obtain the relation

$$
\mathrm{Z}_{\mathrm{s}} / \mathrm{D} \propto(\mathrm{H} / \mathrm{D})^{0.35}
$$

The correlation between $\mathrm{Z}_{\mathrm{s}} / \mathrm{D}$ and $\mathrm{N}_{\mathrm{s}}$ and that between $Z_{s} / D$ and $R e_{s}$ are shown in figures 13 and 14, respectively. From these figures, the following relations are obtained:

$$
\begin{gathered}
\mathrm{Z}_{\mathrm{s}} / \mathrm{D} /(\mathrm{H} / \mathrm{D})^{0.35} \propto \mathrm{Ns}^{3.4}, \\
\mathrm{Z}_{\mathrm{s}} / \mathrm{D} /\left[(\mathrm{H} / \mathrm{D})^{0.35} \mathrm{Ns}^{3.4}\right] \propto \mathrm{Re}^{-0.43}, \\
\mathrm{Z}_{\mathrm{s}} / \mathrm{D}=\mathrm{K}(\mathrm{H} / \mathrm{D})^{0.35} \mathrm{Ns}^{3.4} \operatorname{Re}^{-0.43},
\end{gathered}
$$

where $\mathrm{K}$ is a constant.

According to figure $15, K$ is 0.1 . Thus, for the variable ranges of $\mathrm{H} / \mathrm{D}=0.5-3.0, \mathrm{~N}_{\mathrm{s}}=2.2-3.6$, and $\mathrm{Re}_{\mathrm{s}}=78$ 440 , the following equation is obtained:

$$
\mathrm{Z}_{\mathrm{s}} / \mathrm{D}=0.1(\mathrm{H} / \mathrm{D})^{0.35} \mathrm{~N}_{\mathrm{s}}^{3.4} \operatorname{Res}^{-0.43} \text {. }
$$

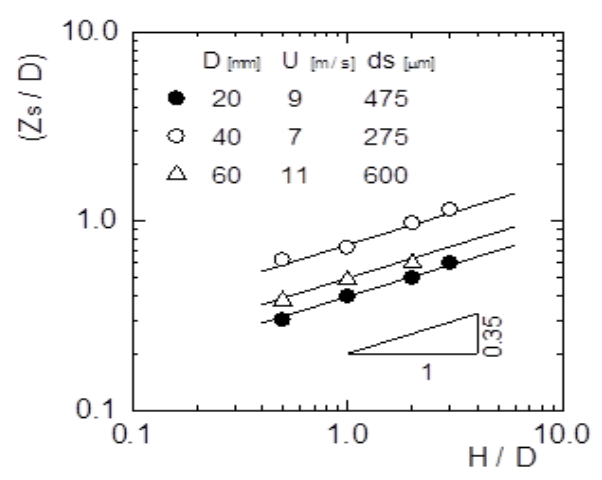

Figure 12. Correlation between scour depth and aspect ratio

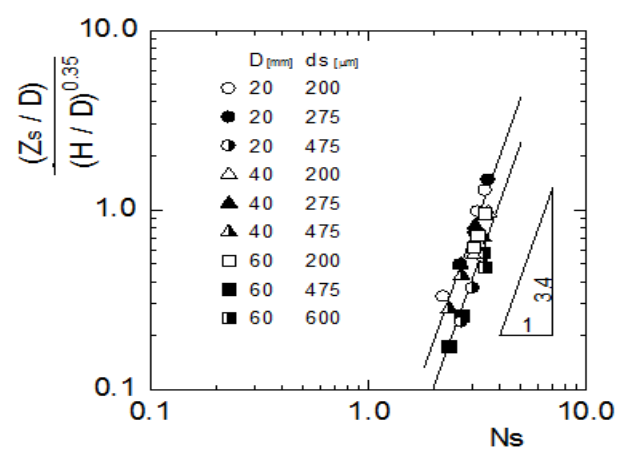

Figure 13. Correlation among scour depth, aspect ratio and sediment number

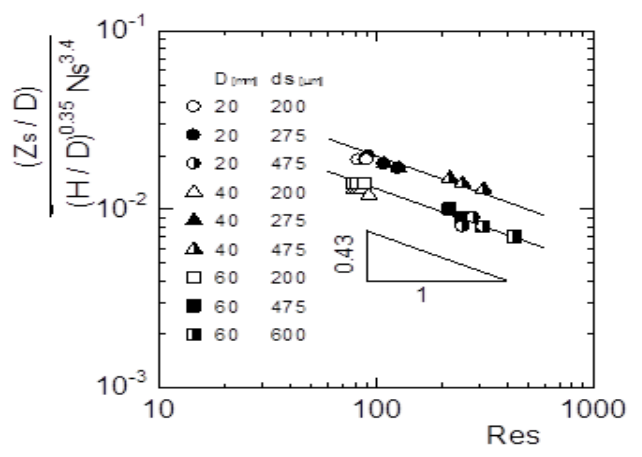

Figure 14. Correlation among scour depth, aspect ratio, sediment number and sediment Reynolds number 


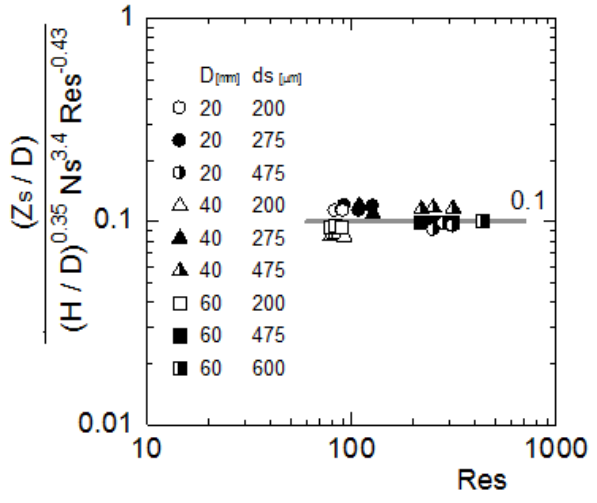

Figure 15. Constant value $\mathrm{K}$

\section{Conclusions}

We measured the scour depth around a cylindrical structure in the sand of a riverbed by using a wind tunnel. The diameter and aspect ratio of the cylindrical structure, the particle size of the bed material, and the fluid velocity were systematically varied. The results are summarized below.

(1) The tendency of the change in the scour depth and radius is the same in air-sand and water-sand systems.

(2) The aspect ratio and particle size significantly influence the scour characteristics.

(3) The relationship between $Z_{s} / D, N_{s}$ and $R_{s}$ is obtained as $Z_{s} / D=0.1(H / D){ }^{0.35} N_{s}{ }^{3.4} \operatorname{Res}^{-0.43}$.

\section{References}

1. H. Mochizuki, Y. Okada, S. Kumar, S. Sinha, J. of Arid Land Studies, 22-1 267-270 (2012)

2. J.H.M. Beyers, P.A. Sundsb申, T.M. Harms, J.Wind Eng. Ind.Aerodyn. 92 725-747 (2004).

3. H. W. Shen, V. R. Schneider, S. Karaki, Proc. ASCE, J. Hyd. Div., 95, HY 6, 1919-1940 (1969)

4. H. N. C. Breusers, G. Nicollet, H. W. Shen, J. Hyd. Research, 15-3, 211-252 (1977)

5. T. Tsutsui, Proceeding of 6 th Int. Colloquium on Bluff Bodies Aerodynamics and Applications (2008), pp.408-411.

6. W. H. Graf, I. Istiarto, J. Hyd. Research 40 (1), 13-20 (2002)

7. R. Pasiok, E. Stilger-szydlo, Archives of Civil and Mechanical Engineering 10 (2), 67-79 (2010)

8. T. Euler, J. Herget, Catena 91,35-46 (2012) 